\title{
Wideband P-Shaped Dielectric Resonator Antenna with Coaxial Probe Feed
}

\author{
Ranjana Singh ${ }^{1}$, Amit Kumar ${ }^{2}$ \\ ${ }^{1}$ (Communication Engineering, Galgotias University, India) \\ ${ }^{2}$ (School of Electrical, Electronics and Communication Engineering, Galgotias University, India)
}

\begin{abstract}
In this paper, design of wideband Coaxial Probe feed P-Shaped Dielectric Resonant Antenna is proposed. The proposed structure has bandwidth of $4.1 \mathrm{GHz}\left(S_{11}<-10 \mathrm{~dB}\right.$ ) ranging from $5.05 \mathrm{GHz}$ to $9.15 \mathrm{GHz}$ which is $85.4 \%$ of total bandwidth from $4.5 \mathrm{GHz}$ to $9.3 \mathrm{GHz}$. Antenna has return loss of $-61.29 \mathrm{~dB}$ that is only a micro part of input power is reflected back resulting to a highly efficient antenna. Designed antenna is a low profile antenna with height of $10 \mathrm{~mm}$.Resonant frequency of proposed antenna is $6.14 \mathrm{GHz}$, suitable for wireless system like WiMAX, WLAN, C-band applications. Simulation and parametric analyses of proposed P-shaped antenna is done using CST (Computer Simulation Technology) Microwave Studio Suite 10.
\end{abstract}

Keywords: Dielectric resonator antenna (DRA), Impedance bandwidth (IBW), Perfect conductor, Resonant frequency, Return loss $\left(S_{11}\right)$.

\section{Introduction}

Recently extensive research has been done to achieve wide bandwidth and high radiation efficiency for DRA using different configuration and design aspects. DRAs are low profile antennas means they have light weight, low cost and compact size. Moreover, they offer greater design flexibility and mechanical simplicity [13]. DRAs have zero conduction losses thus a major problem of conductor losses in metallic antennas is overcome by dielectric resonators antennas [4]. Additionally, they offer primary features like different methods of excitations such as coaxial probe feed, micro-strip feed, ease of coupling to almost all type of transmission lines, low temperature coefficient and high radiation efficiency [3]. DRAs are available in rectangular, triangular, spherical, conical and cylindrical shapes, where rectangular DRA offer maximum design flexibility (have two aspect ratios width/height and length/height) [5]. One more advantage of rectangular DRA is reduction of mode degeneracy problem which offer optimized bandwidth [6]. Over the last decades, main area of interests is to broaden the bandwidth of DRA. For the same, compact DRAs such as embedded DRA or DRAs with different configuration and shapes (L-shaped [7], T-shaped [8], tetrahedron [9], stair case [10] and so on) with different feeding mechanism were introduced. By using these DRAs bandwidth was increased up to only 50\%-60\% [7-10]. Recently P-shaped DRA with micro-strip feed was introduced which offers bandwidth of 80\% [11]. This paper presents designing of P-shaped DRA excited by coaxial probe which enhances the bandwidth of DRA up to $85.4 \%$ from $5.05 \mathrm{GHz}$ to $9.15 \mathrm{GHz}$. This paper is organized in different sections as basic theory is explained in Section II, Antenna configuration and Parametric Study/Results are in Section III and Section IV respectively. Paper is concluded in Section V.

\section{Theory}

To design proposed structure rectangular DRA is chosen. Field inside rectangular DRA is similar to rectangular dielectric waveguide and the propagation modes are divided into TE and TM modes but due to mounting of DRA over ground plane only TE modes- $T E^{x}, T E^{y}$ and $T E^{z}$ are excited [12]. The resonant frequency of these modes is a function of DRA dimensions. By using equation of magnetic wall waveguide model, initial dimensions of DRA are calculated considering $m=n=1$ and dielectric in $\mathrm{x}-\mathrm{z}$ direction [13-14]. To calculate wave number equations are derived after implying magnetic wall boundary conditions, these equations are-

$$
\begin{aligned}
k_{x} & =\frac{m \pi}{a} \\
k_{y} & =\frac{n \pi}{b} \\
k_{z} \tan \left(\frac{h k_{z}}{2}\right) & \left.=\sqrt{\left(\epsilon_{x}\right.}-1\right)\left(k_{o}^{2}-k_{z}^{2}\right) \\
k_{x}+k_{y}+k_{z} & =\varepsilon_{r}
\end{aligned}
$$

Where $k_{x}, k_{y}$ and $k_{z}$ are wave numbers in $\mathrm{x}, \mathrm{y}$ and $\mathrm{z}$ directions respectively and $\mathrm{k}_{\mathrm{o}}$ denotes wave number in free space, defined as:

$$
k_{o}=\frac{2 \pi f_{o}}{c}
$$


Thus, resonant frequency can be calculated using equation:

$$
f_{o}=\frac{c}{2 \pi} \sqrt{\left\{\frac{1}{\left(\varepsilon_{r}-1\right)}\right.}\left[k^{2} \tan ^{2}\left(\frac{d k_{x}}{2}\right)+k_{x}\right\}
$$

There is trade-off between bandwidth and Q-factor. Higher Q-factor lowers the bandwidth whereas Qfactor increases with increase in dielectric constant. Thus to achieve greater bandwidth material with lower dielectric constant should be used [15-17]. By removal of a part from rectangular DRA also reduces Q-factor resulting increase in bandwidth.

\section{Design And Antenna Configuration}

To design P-shaped DRA, first of all a rectangular part of dimension $(p \times q \times h)$ is removed from a rectangular DRA of dimension $(w \times d \times h)$ as shown in Fig. 1(b). In second step another rectangular part of dimension $(u \times v \times h)$ is separated from the structure obtained in first step, final structure is shown in Fig. 1(c) [2].

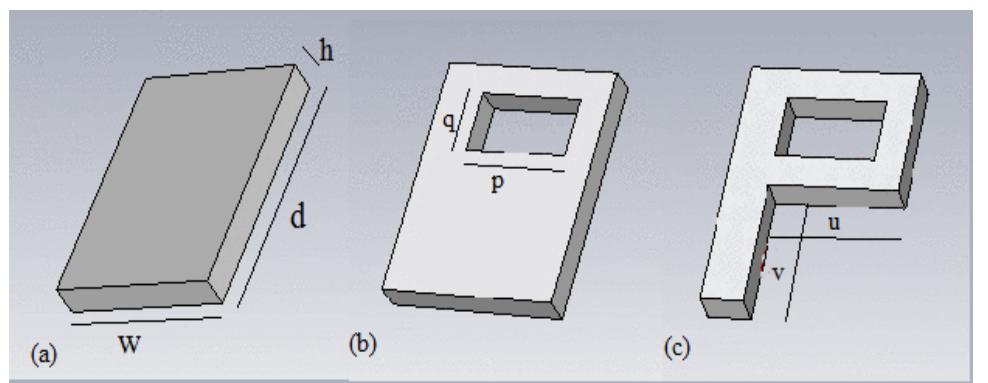
Figure 1
(a) Rectangular DRA
(b) DRA with hole
(c) P-shaped DRA

To reduce the value of Q-factor a hole of $(p \times q \times h)$ is drilled where $\mathrm{p}=6 \mathrm{~mm}$ and $\mathrm{q}=4 \mathrm{~mm}$, same as values of other removed section is $u=v=8 \mathrm{~mm}$. Fig. 2 shows $3 \mathrm{D}$ and back view of proposed P-shaped DRA with coaxial probe feed. DRA is mounted over ground plane which is a perfect conductor. This ground plane has dimensions- width- $16 \mathrm{~mm}$, length- $18 \mathrm{~mm}$ and height $-1.5 \mathrm{~mm}$. Proposed antenna is designed using material Beryllia of dielectric constant $\varepsilon_{\mathrm{r}}=6.5$. Beryllia has thermal conductivity $330 \mathrm{~W} / \mathrm{K} / \mathrm{m}$, Young's modulus 345 $\mathrm{kN} / \mathrm{mm}^{2}$, Poisson's ratio of 0.26 and thermal expansion of $7\left[1 \mathrm{e}^{-6 / K}\right]$. Dielectric resonator is characterized by dimensions $\mathrm{w}, \mathrm{d}$ and $\mathrm{h}$ having values $12 \mathrm{~mm}, 16 \mathrm{~mm}$ and $10 \mathrm{~mm}$ respectively. DRA is excited by a $z$-directed coaxial probe whose radius is $r=0.5 \mathrm{~mm}$ which is insulated by Teflon coating having inner radius of $r=0.5 \mathrm{~mm}$ and outer radius $R=1.67 \mathrm{~mm}$ to have matching impedance of $50 \mathrm{ohm}$. Values of $r$ and $R$ are calculated using line impedance calculator to have optimum matching. Coaxial probe is inserted from the back side of the ground plane at the lower end of DRA as shown in Fig. 2(a).

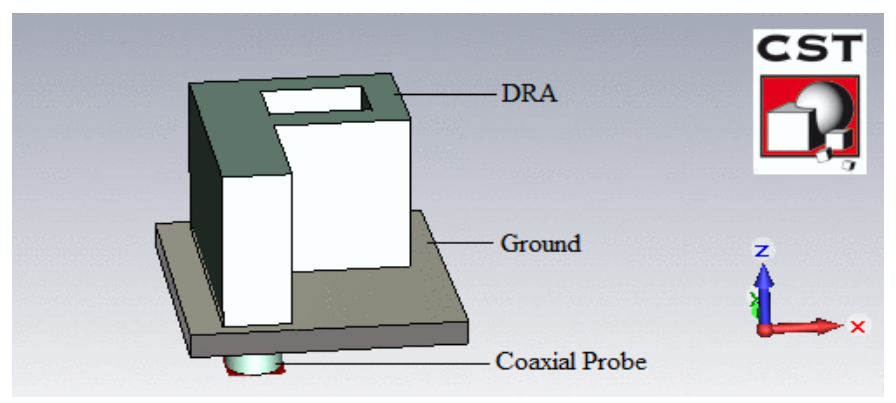

(a)

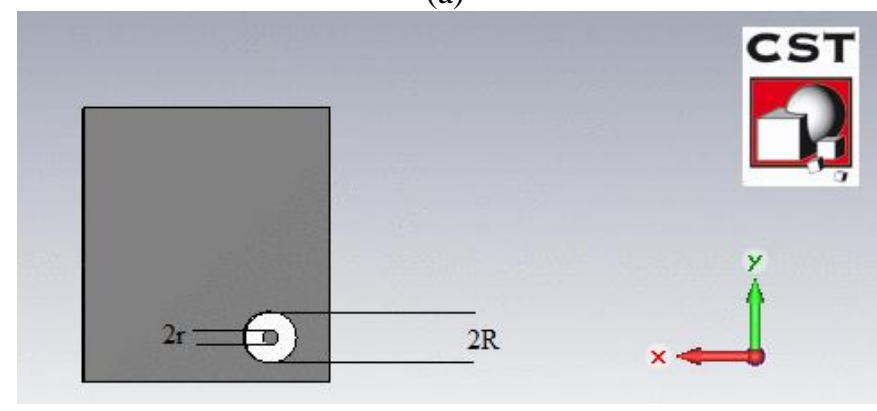

(b)

Figure 2. (a) 3D view and (b) back view of proposed P-shaped DRA 
As in Fig. 2(b) ground and probe is insulated by Teflon whose material density is $2200 \mathrm{~kg} / \mathrm{m}^{3}, \mu_{\mathrm{r}}=1$, $\varepsilon_{\mathrm{r}}=2.1$, thermal conductivity is $0.2 \mathrm{~W} / \mathrm{K} / \mathrm{m}$, Young's modulus $0.5 \mathrm{GPA}$, thermal expansion coefficient $140\left[1 \mathrm{e}^{-}\right.$ $6 / \mathrm{K}$ ] and Poisson's ratio of 0.4. Design presented in [2] has been enhanced and the simulated results are presented. To design proposed structure material with lower dielectric constant is used which is cheaper and easy to machine. Probe is a PEC and its length is $11.5 \mathrm{~mm}$ out of which $8 \mathrm{~mm}$ is inserted into the DRA and $2 \mathrm{~mm}$ is below to the ground. Only $3.5 \mathrm{~mm}$ length of probe is coated by Teflon.

\section{Results And Parametric Analysis}

Proposed structure is examined and simulated using CST Microwave Studio-10, $\mathrm{S}_{11}$ parameter is shown in Fig. 3. According to this simulation resonant frequency is at $6.14 \mathrm{GHz}$ and bandwidth of $4.1 \mathrm{GHz}$ $\left(\mathrm{S}_{11}<-10 \mathrm{~dB}\right)$ from 4.5 to $9.3 \mathrm{GHz}$. Fig. 3 shows that maximum dip is at $6.14 \mathrm{GHz}$ and at this frequency return loss is $-61.29 \mathrm{~dB}$. Gain of the antenna is $2.4 \mathrm{~dB}$ and its Far-field radiation pattern is shown in Fig. 4. Impedance bandwidth of antenna is calculated using equation IBW $=\frac{f_{h}-f_{l}}{f_{c}}$, where $f_{h}$ is higher cut-off frequency, $f_{l}$ is lower cut-off frequency and $f_{c}$ is center frequency. It is found that impedance bandwidth is $65 \%$. Voltage standing wave ratio (VSWR) is the measure of how perfectly antenna is matched with transmission line. It is expressed as $\operatorname{VSWR}=(1+\Gamma) /(1-\Gamma)$, where $\Gamma$ is reflection coefficient or return loss. From Fig. 5 it is found that VSWR is 1.001 , which is way below 2 .

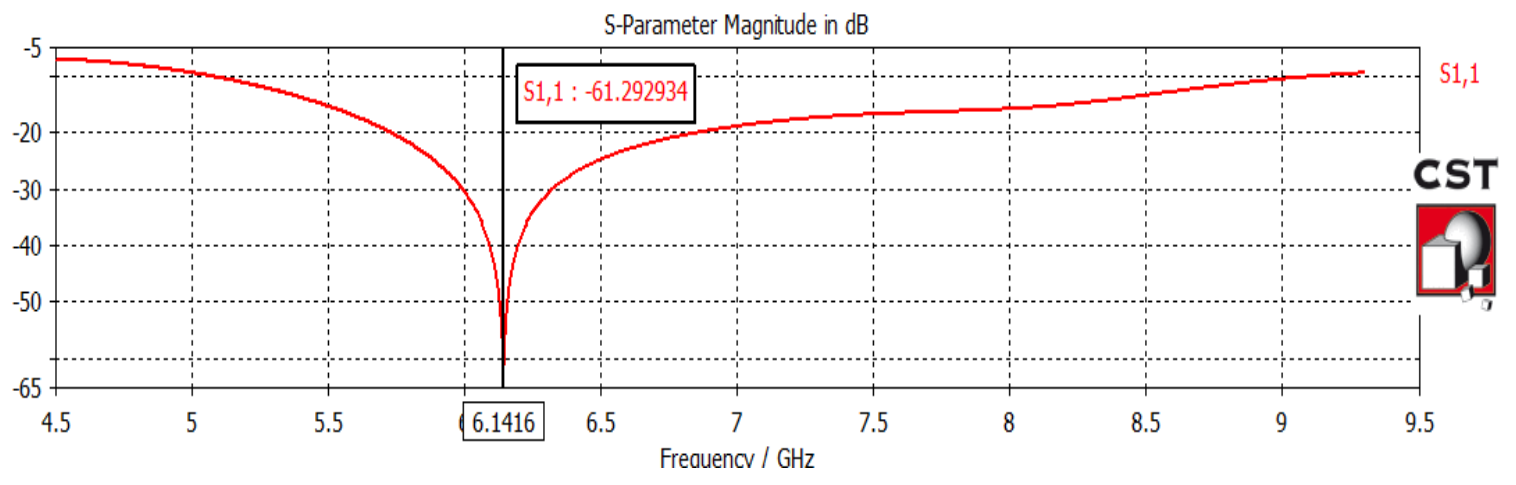

Figure 3. $\mathrm{S}_{11}$ Parameter of proposed antenna.

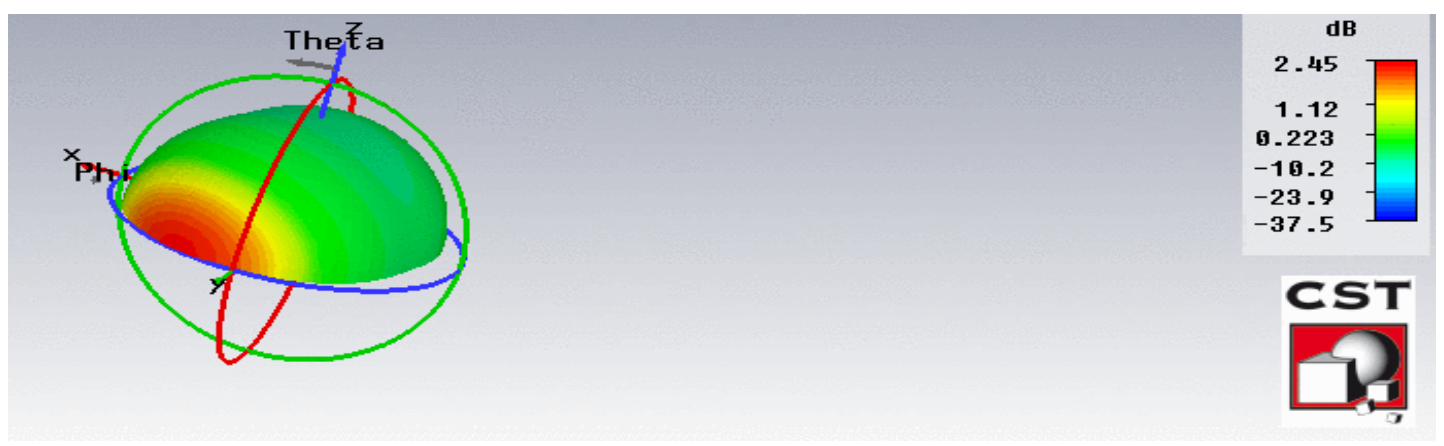

Figure 4. Far-field radiation pattern.

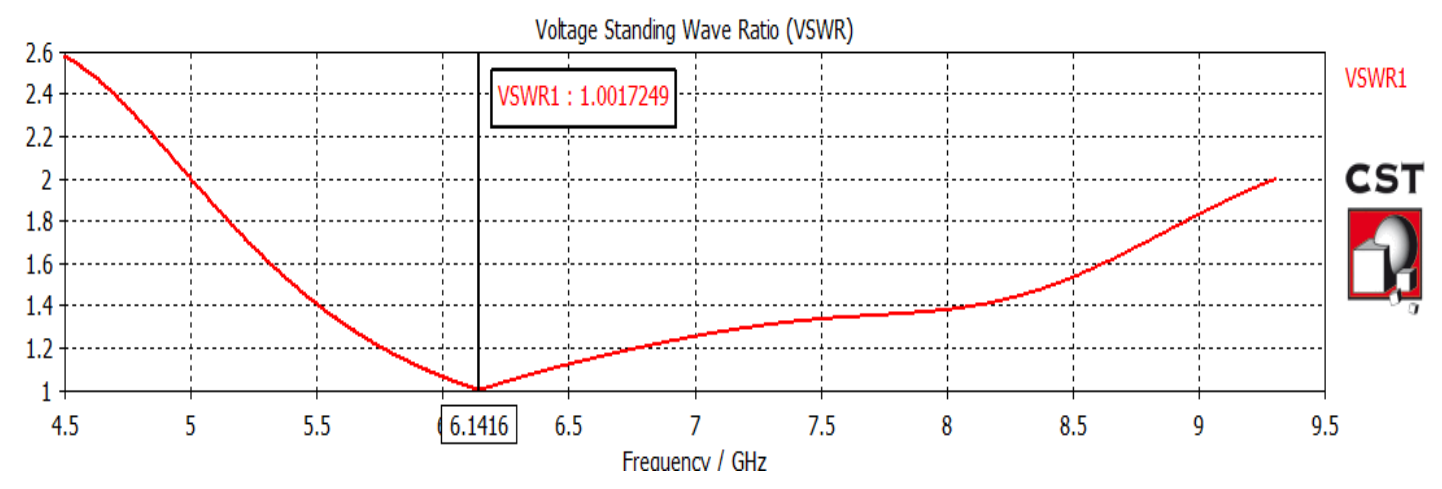

Figure 5. VSWR Representation at Resonant frequency. 
E-field should have a regular converging pattern, form Fig. 6(a) it can be analyze that E-fields are converging at the center of Probe. Fig. 6(b) shows H-field radiation pattern.
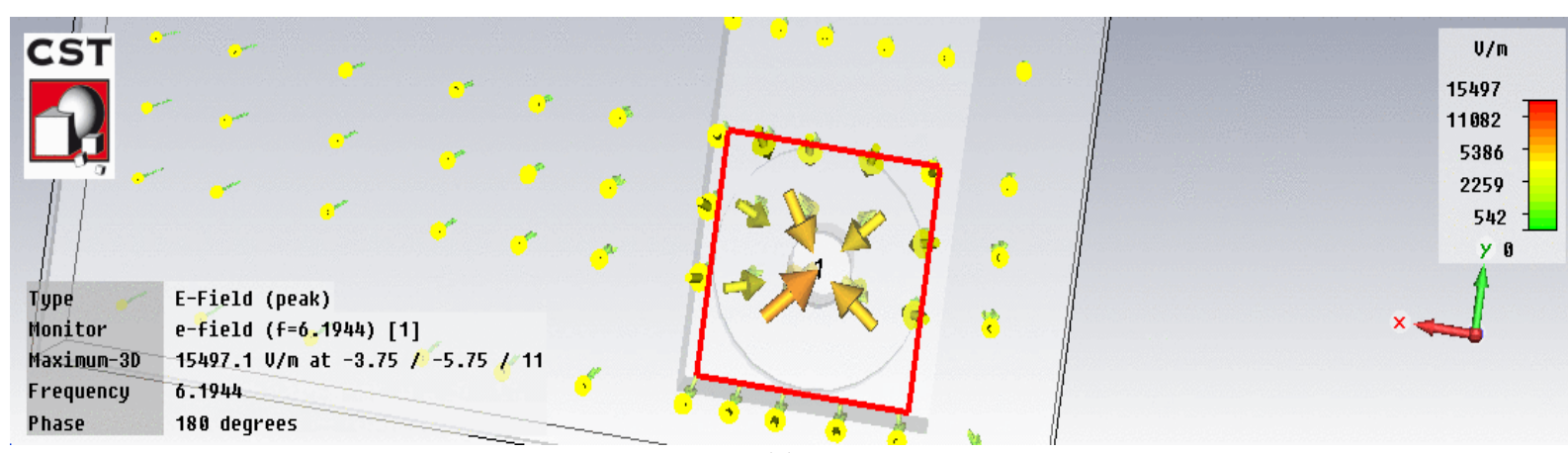

(a)
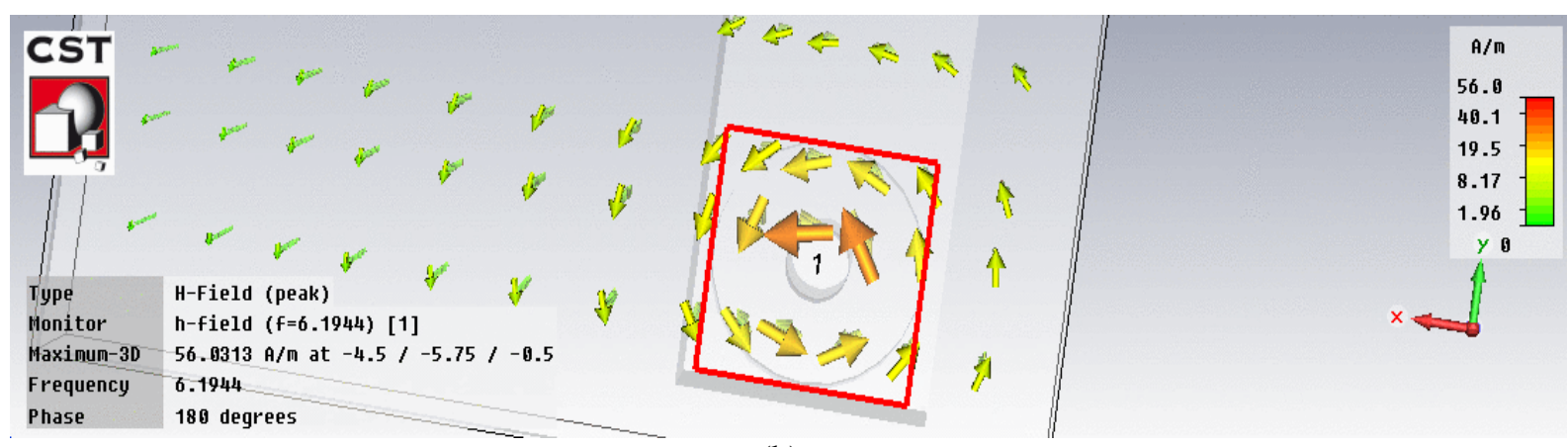

(b)

Figure 6. (a) E-field pattern (b) H-field pattern.

For better understanding of proposed DRA, parametric study is performed to see the effect on the reflection coefficient and impedance bandwidth. In Figure 7, height of antenna (h) is varied and related impedance bandwidth is calculated and presented in Table I.

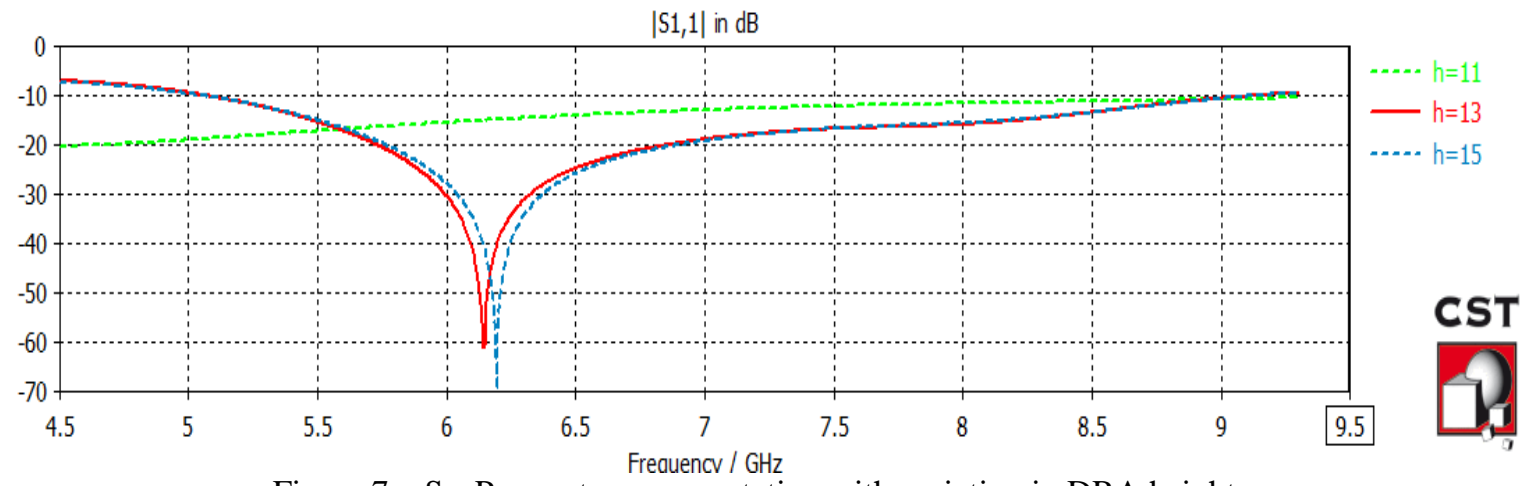

Figure 7. $\mathrm{S}_{11}$ Parameter representation with variation in DRA height.

TABLE I. Impedance Bandwidth for Different Heights of DRA.

\begin{tabular}{|c|c|c|c|c|}
\hline Height of DRA (h) & Range $\left(\mathbf{f}_{\mathbf{h}}-\mathbf{f}_{\mathbf{l}}\right)$ & $\begin{array}{c}\text { Resonant } \\
\text { frequency(GHz) }\end{array}$ & Bandwidth(GHz) & IBW \\
\hline 11 & - & - & - & - \\
\hline 13 & $9.15-5.05$ & 6.14 & 4.1 & $66.77 \%$ \\
\hline 15 & $9.05-5.25$ & 6.23 & 3.8 & $60.99 \%$ \\
\hline
\end{tabular}




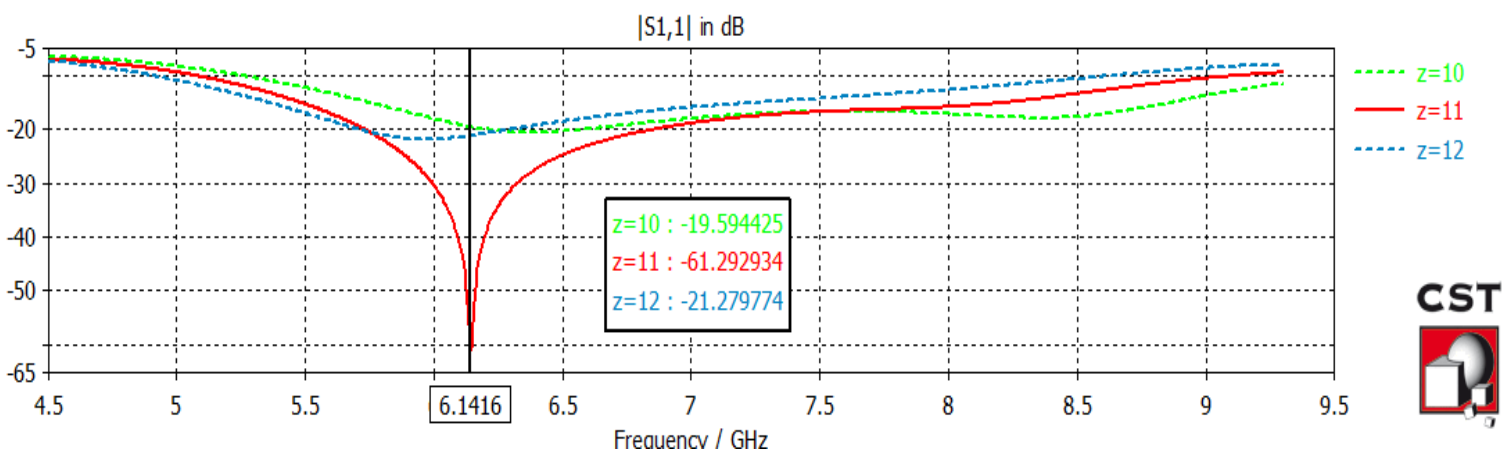

Figure 8. $\mathrm{S}_{11}$-Parameter with variation in length of coaxial probe.

In Fig. $8 \mathrm{z}$ is representing the co-ordinate from -0.5 to 11 with ground plane having $\mathrm{z}$ co-ordinate ranging from 1.5 to 3, it can be seen in Fig. 1(a) that probe is z-directed. It is clear from Fig. 8 that when probe length is varied, reflection coefficient is also varying; best result comes when the probe is inserted into the DRA up to the length of $8 \mathrm{~mm}$. Fig. 9 presents simulated result of $S_{11}$ Parameter when point of feeding is varied (in $y$ direction which can be seen in Fig. 1(b). Results are taken at three positions, at lower end $(y=-6)$, at upper side $(\mathrm{y}=6)$ and at middle $(\mathrm{y}=0)$ with $\mathrm{x}$ co-ordinate at -4 taking center of antenna $(\mathrm{x}=0, \mathrm{y}=0)$. We have best result when probe is at lower end.

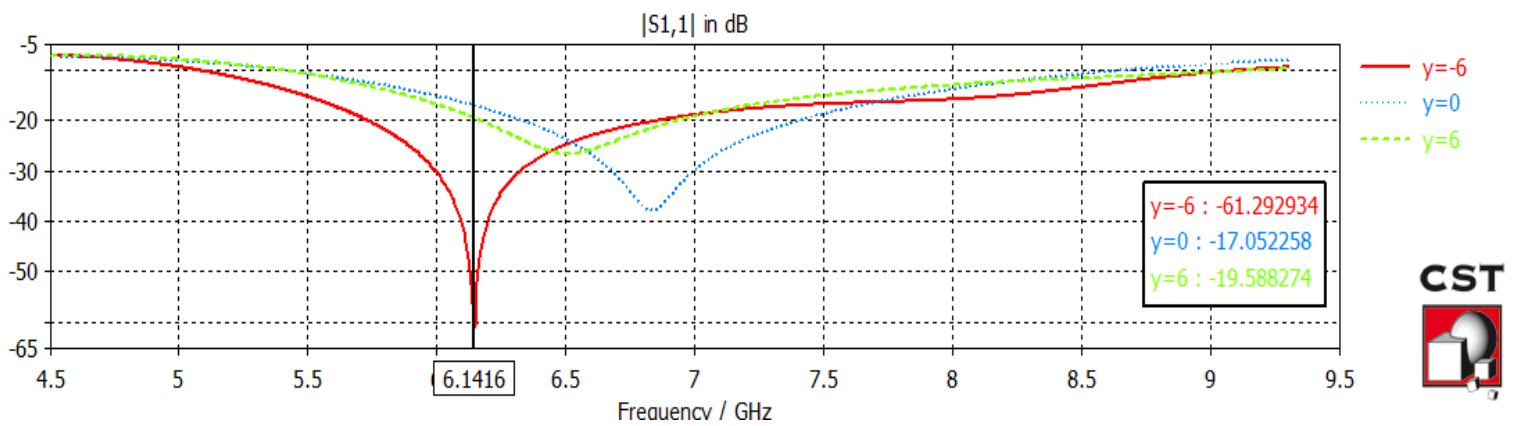

Figure 9. $\mathrm{S}_{11}$-Parameter representation when feeding position is varied.

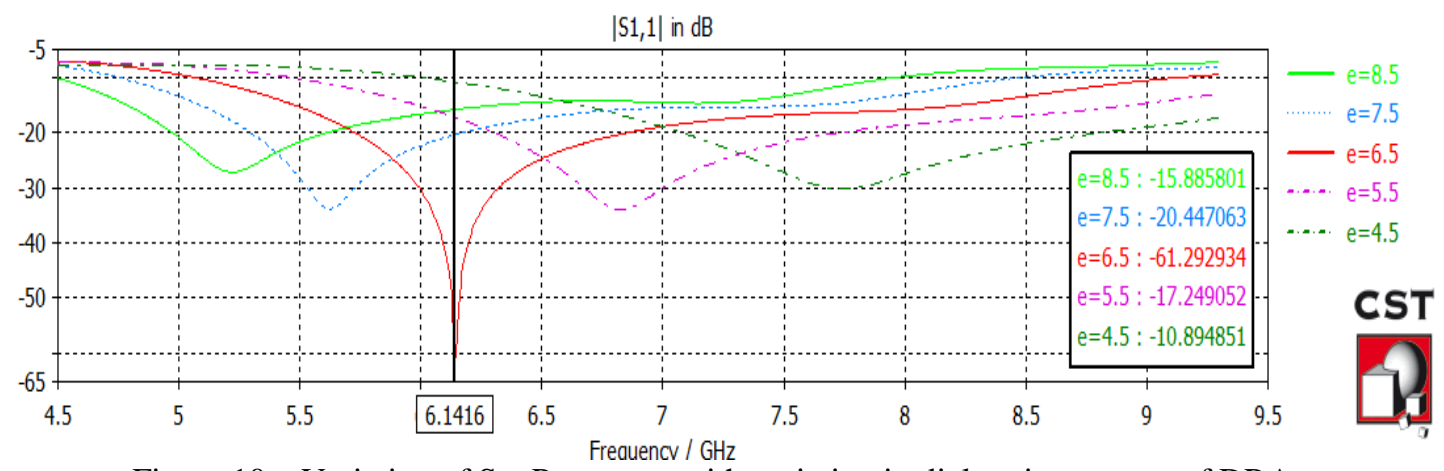

Figure 10. Variation of $S_{11}$-Parameter with variation in dielectric constant of DRA.

When dielectric constant is varied it is observed that either dielectric constant value is increased or decreased return loss increases. At $\varepsilon_{r}=6.5$ return loss is $-61.29 \mathrm{~dB}$ and impedance bandwidth is maximum. Table II shows the change in impedance bandwidth and $\mathrm{S}_{11}$ parameter as dielectric constant is varied.

Table II. Reflection Coefficient and Impedance Bandwidth when Dielectric Constant is varied.

\begin{tabular}{|c|c|c|c|c|}
\hline Dielectric Constant & Reflection Coefficient(dB) & Resonant frequency(GHz) & Bandwidth(GHz) & IBW \\
\hline 4.5 & -30 & 7.72 & 3.42 & $44.30 \%$ \\
\hline 5.5 & -34 & 6.82 & 3.75 & $54.98 \%$ \\
\hline 6.5 & -61.29 & 6.14 & 4.10 & $66.77 \%$ \\
\hline 7.5 & -32 & 5.62 & 3.62 & $64.44 \%$ \\
\hline 8.5 & -28 & 5.23 & 3.30 & $63.0 \%$ \\
\hline
\end{tabular}




\section{Conclusion}

Proposed P-shaped antenna is examined which is excited by a coaxial probe and it is found that proposed structure is a low profile antenna, widely applicable for wireless application systems like WLAN, WiMAX and C-band. From simulated result it is observed that proposed antenna is a wideband antenna of bandwidth $4.1 \mathrm{GHz}$ (where $\mathrm{S}_{11}<-10 \mathrm{~dB}$ ). Resonant frequency is calculated using an approximate equation which is $6.14 \mathrm{GHz}$ and gain at this frequency is $2.45 \mathrm{~dB}$. VSWR is found $1.001 .85 .4 \%$ frequency is useful from total supplied frequency with impedance bandwidth of $66.77 \%$, which makes it an ultra-wideband antenna.

\section{References}

[1] R.K. Mongia and A. Ittipiboon, "Theoretical and experimental investigations on rectangular dielectric resonator antenna," IEEE Trans. Antennas Propagation., vol. 45, no. 9, pp. 1348-1356, Sep. 1997.

[2] Mohsen Khalily, Md. Kamal A. Rahim, Ahmed A. Kishik, Shadi Danesh, "Wideband P-Shaped Dielectric Resonator Antenna," Radio-engineering, vol. 22, No. 1, April 2013.

[3] Bin LI, Kwok Wa Leung, "Strip-Fed Rectangular Dielectric Resonator Antennas With/Without a Parasitic Patch," IEEE Transaction On Antennas And Propagation, vol. 53, NO. 7, July 2005.

[4] Debatosg Guha, Yahia M. M. Antra, "Four-Element Cylindrical Dielectric Resonator Antenna for Wideband Monopole-Like Radiation," IEEE Transaction on Antenna and Propagation," vol. 54, no. 6, Sept. 2006.

[5] M. F. Ain, Y. M. Qasaymeh, Z. A. Ahmed, M. A. Zakariya, M. A. Othman, A.S. Sulaiman, S. D. Hutaga lung and M. Z. Abdullah, “A Novel 8.5 GHz Array Dielectric Resonator Antenna,” Progress In Electromagnetics Research C, vol. 15, 201-210, 2010.

[6] M. C. McAllister, G.L. Conway and S. A. Long, "Rectangular dielectric-resonator antenna," Electron Letter, pp. 218-219, March 1983.

[7] J. K. Plourde and C. Ren, “Application of Dielectric Resonators in Microwave Components," IEEE Transactions on Microwave Theory and Techniques, vol. MTT-29, no. 8, pp. 754-770, August 1981.

[8] Mongia, R.K., et al., "Accurate Measurement of Q-factor of Isolated Dielectric Resonator," IEEE Transactions on Microwave Theory \& Techniques, vol. 42, no. 8, pp. 1463-67, Aug. 1994.

[9] Amit Kumar, Utkarsh Besaria, Rajeev Gupta, "Four-Element Triangular Wideband Dielectric Resonator Antenna excited by a Coaxial Probe," IOSR Journal of Electronics and Communication Engineering, vol 6, no 4, pp. 01-06, June 2013.

[10] H.Y. Lo, K. W. Leung, K.M. Luk, and E.K.N. Yung, "Low profile triangular dielectric resonator antenna," IEEE Antennas and Propagation Society International Symposium, vol. 4, pp. 2088-2091, July 2000.

[11] S. A. Long, M. W. McAllister and L.C. Shen, "The resonant cylindrical dielectric cavity antenna," IEEE Transactions on Antennas Propagation, pp. 406-412, April 1983.

[12] Almpanis, G., Fumeaux, Ch., Vahldieck, R., "The trapezoidal dielectric resonator antenna," IEEE Trans. on Antennas and Propagation, vol. 56, no. 9, pp. 2810-2816, 2008.

[13] Rao, Q. J., Denidni, T. A., Sebak, A. R., "Broadband compact stacked T-shaped DRA with equilateral-triangle cross sections," IEEE Antenna Wireless Propag. Lett, vol. 5, pp. 130-133, 2006.

[14] Yoshihiko Akaiwa, "Operation Modes of a Waveguide Y Circulator," IEEE Transactions on Microwave Theory \& Techniques, pp. 954-960, Nov 1974.

[15] R. A. Kranenburg, S. A. Long, "Microstrip Transmission Line Excitation of Dielectric Resonator Antennas," IEE Electronics Letters, 24, 18, pp. 1156-1157, 1988.

[16] A. A. Kishk, X. Zhang, A. W. Glisson, and D. Kajfez, "Numerical analysis of stacked dielectric resonator antennas excited by a coaxial probe for wideband applications," IEEE Trans. Antennas Propagation, vol. 51, no. 8, pp. 1996-2006, Aug. 2003.

[17] M. Lapierre, Y.M.M.Antar, A.Ittipiboon andA.Petosa, "Ultra wide-band monopole/dielectric resonator antenna," IEEE Ramkakm Microwave Wireless Compon. Lett. vol. 15, no. 1, pp. 7-9, 2005. 